\title{
Notes on Pygophora Schiner, 1868 (Diptera: Muscidae) from New Guinea
}

\author{
Заметки о Pygophora Schiner, 1868 (Diptera: Muscidae) \\ из Новой Гвинеи
}

\author{
Nikita E. Vikhrev \\ Никита Е. Вихрев
}

Zoological Museum of Moscow University, Bolshaya Nikitskaya 6, Moscow 125009, Russia. E-mail: nikita6510@ya.ru
Зоологический музей, МГУ им. М.В. Ломоносова, Большая Никитская ул., 6, Москва 125009, Россия.

\author{
KEY WORDS: Pygophora, Muscidae, Diptera, New Guinea \\ КЛЮЧЕВЫЕ СЛОВА: Pygophora, Muscidae, Diptera, Новая Гвинея
}

\begin{abstract}
Five New Guinean species of Pygophora Schiner, 1868 are considered. One new species $P$. papuana sp.n. and 3 hitherto unknown females of $P$. absentiseta Crosskey, 1962, P. enigma Crosskey, 1962 and $P$. luteicornis Walker, 1858 are described. Two new syno-nymies are proposed: Pygophora longipila Stein, $1910=P$. nitidiventris Malloch, 1929, syn.n. = P. orbiculata Cui et Zhang, 1995, syn.n.
\end{abstract}

РЕЗЮМЕ. Рассмотрены 5 видов Pygophora Schiner, 1868 , описанных из Новой Гвинеи. Описан 1 новый вид: P. papuana sp.n., и дано описание 3 неизвестных до настоящего времени самок P. absentiseta Crosskey, 1962, P. enigma Crosskey, 1962 and P. luteicornis Walker, 1858. Предложено 2 новый синонима: Pygophora longipila Stein, $1910=P$. nitidiventris Malloch, 1929, syn.n. $=P$. orbiculata Cui et Zhang, 1995, syn.n.

\section{Introduction}

Genus Pygophora Schiner, 1868 includes about 7580 valid (or so far valid) species.

Crosskey [1962] made a detailed revision of the World fauna of Pygophora with a generic diagnosis and key and gave descriptions of 53 species known at that time. Since that 12 more species from Oceania were described (mostly by Snyder [1965]) and about 15 species were described from China by Chinese authors [Cui et al., 1995; Xue, Zhang, 2013]. Pygophora is distributed in the tropical Asia, Melanesia, Micronesia, Australia and Africa, with a supposed center of diversity in Indonesia. No wonder that New Guinea with vast lowlands and extensive mountain areas has the richest fauna of Pygophora. Nothing was published on New Guinean Pygophora since Crosskey's [1962] revision.

During the recent trip to West Papua in December 2014 an interesting material on Pygophora was col- lected. Partly this material should wait until the taxonomic problems will be resolved. But the situation with 5 species considered in the present paper seems to me clear and the new data worth to be published. The male from highland Lake Habbema undoubtedly belongs to an undescribed species with atypical morphology and ecology. Three more species (Pygophora absentiseta Crosskey, 1962, P. luteicornis Walker, 1858 and $P$. enigma Crosskey, 1962) were collected at Baliem Resort in representative series of both sexes, that permitted me to give here the descriptions of unknown females of these species and specify some characters of males. At last $P$. longipila Stein, 1910 considered here on material formerly collected in Thailand, but the type locality of this species is again New Guinea.

\section{Material and methods}

The specimens listed are in the Zoological Museum of Moscow University (not indicated in text) Localities are given as follows: country, region, geographical coordinates in the decimal degrees format.

The following generally accepted abbreviations for morphological structures are used: $f 1, t 1, f 2, t 2, f 3, t 3=$ fore-, mid-, hind- femur or tibia respectively; $a c$ acrostichal setae; $d c$ - dorsocentral setae; $a, p, d, v=$ anterior, posterior, dorsal, ventral seta(e).

For life images of Pygophora Canon 20D with lens $100 \mathrm{~mm}$ Macro was used.

Pygophora absentiseta Crosskey, 1962

Fig. 3.

Pygophora absentiseta Crosskey, 1962. Type locality: New Guinea. Type series consists of $\sigma^{7}$ holotype and $6 \sigma^{7} \sigma^{7}$ paratypes, all from New Guinea from altitudes from 1450 to $3000 \mathrm{~m}$ asl.

MATERIAL. Indonesia, W Papua prov., Wamena env., Baliem Resort, $2000 \mathrm{~m}$ a.s.1., $4.06^{\circ} \mathrm{S} 139.03^{\circ} \mathrm{E}, 16-25.12 .2014$, N. Vikhrev, $13 \sigma^{\top} \sigma^{7}, 6$ 우.

NOTES ON MALE. I have only few additions to Crosskey's [1962] detailed description. 
f2: 5-6 av setae in basal half; 3-4 long fine sparse $p v$ setae in basal $2 / 3$ and a dense set of 5 short $p v$ spinulose seta at very apex. $f 3: 2 a v$ in basal $1 / 3$ and 2 $a v$ in apical 1/3; on $p v$ surface 1 long strong $p v$ at basal $1 / 3$ and about 10 short $p v$ spines (like that in Pygophora buxtoni Malloch, 1929 [Crosskey, 1962: 531, Fig. 27], but more ventrally situated). $t 3$ as in [Crosskey, 1962: 447], but long strong $p v$ seta in basal $1 / 3$ was described as "slightly hooked at the apex". As illustrated on Fig. 3 this $p v$ seta is not slightly but very remarkably hooked.

DESCRIPTION OF FEMALE. Body length: 5.5$5.7 \mathrm{~mm}$. Head. Frons yellow-brown. Face, gena and occiput grey. Supernumerary inclinate setae absent. Antenna dark, only base of postpedicel yellow-brown; postpedicel rather short, falling mouth margin by 0.4 of its length; postpedicel 5 times as long as wide. Thorax black. Scutum dark-grey dusted with black median and pair of submedian vittae; scutal vittae are distinct either on post- and presutural areas. Presutural $a c$ in 2 rows. Legs. Coxae dark; trochanters yellow; femora black, but $f 3$ dirty-yellow in basal $1 / 3-1 / 4$; tibiae yellow. $t 1$ with 1 long $p v$ and 2 short $a d$. Mid coxa without pair of long appressed setae. $f 2$ in basal half with 7-8 medium long $a v ; 3$ long $p v$ and 2 preapical $p d$. $t 2$ with $2 p d . f 3$ with irregular row of 5-6 av and 3 long $p v$ in basal part. $t 3$ with $1 a v, 2 a d, 2 p d$. Abdomen black with dense grey dusting except for yellowish lateral part of tergite $1+2$. Tergites 3 to 5 with large black median and lateral spots. Remarks. Supposed females of $P$. absentiseta mentioned by Crosskey [1962: 448] probably belong to some other species, because otherwise Crosskey would pay attention on the uncommon dark colour of the antenna.

\section{Pygophora enigma Crosskey, 1962 Figs 4-5.}

Pygophora enigma Crosskey, 1962. Type locality: Papua New Guinea, Mt. Otto, $2200 \mathrm{~m}$ a.s.1. $\left(6.02^{\circ} \mathrm{S} 145.45^{\circ} \mathrm{E}\right)$. Paratype $1 \mathrm{O}^{7}$ Papua New Guinea, E of Kainantu, $1350 \mathrm{~m}$ asl (6.25S 146.35E).

MATERIAL. Indonesia, W Papua prov., Wamena env., Baliem Resort, $2000 \mathrm{~m}$ a.s.1., $4.06^{\circ} \mathrm{S} 139.03^{\circ} \mathrm{E}, 16-25.12 .2014$, N. Vikhrev, $4 \mathrm{O}^{\top} \sigma^{\top}, 2$ 우.

NOTES ON MALE (Fig. 4). In contrast to Crosskey's description specimens from Baliem Resort have a supernumerary pair of inclinate setulae (though short and fine) and the anterior part of fronto-orbital plates with 5-7 minute hairs. Aristal hairs as in Fig.4: hairs unusually short, lower hairs distinctly shorter than upper ones.

DESCRIPTION OF FEMALE (Fig. 5). Body length: 4.6-4.8 mm. Head. Frons unusually wide (at level of anterior pair of reclinate setae about $1 / 3$ of head width). Antenna and frons dirty blackish-brown, fronto-orbital plates and pafacials brownh-grey, occiput dark grey. Fronto-orbital plates in anterior $1 / 3$ with 5-7 minute hairs and supernumerary pair of short and fine (though stronger than in males) inclinate setulae. Arista with the longest hairs $1-1.5 \mathrm{x}$ as long as antenna width; upper hairs only slightly longer that lower ones; arista plumose in basal 2/3. Thorax dark, scutum black with only very thin grey dusting, pleura dusted grey. Presutural $a c$ in 2 rows. Legs entirely yellow including coxae. $t 1$ with 1 long $p v$, without $a d$. $f 2$ with 3 long $p v$ in basal half and and 2 preapical $p d$. $t 2$ with $2 p d$. $f 3$ with 3 long $a v$ in apical half and $2 p v$ in basal half. $t 3$ with 1 av, 2 ad, 2 pd. Abdomen. Tergite $1+2$ yellow with small dorsal blackish spot; tergites 3 yellow with bigger black spot dorsally; tergites 4 and 5 black, narrowly yellow on posterior margin and ventrally.

\section{Pygophora longipila Stein, 1910 Figs 6-7.}

Pygophora longipila Stein, 1910. Type locality: Papua New Guinea, Simbang $\left(6.58^{\circ} \mathrm{S} 147.83^{\circ} \mathrm{E}\right)$. Only $\sigma^{\prime}$ lectotype remains from type series of $3 \bigcirc^{\top} \sigma^{\top}$ and 2 우.

Pygophora nitidiventris Malloch, 1929, syn.n. Type series: Indonesia, Buru Isl., + holotype; Indonesia, Sumatra, Fort de Kock (= Bukittinggi, $\left.0.3^{\circ} \mathrm{S} 100.4^{\circ} \mathrm{E}\right), 925 \mathrm{~m}$ a.s.1., ${ }^{\circ}$ paratype; Malaysia, Selangor, Bukit Kutu $\left(3.54^{\circ} \mathrm{N} 101.72^{\circ} \mathrm{E}\right), 1060 \mathrm{~m}$ a.s.1., + paratype.

Pygophora orbiculata Cui et Zhang, 1995, syn.n. Type locality: China, Yunnan prov., Xishuangbanna (Dai Autonomous Prefecture) $\left(22.0^{\circ} \mathrm{N} 100.8^{\circ} \mathrm{E}\right)$ (coordinates given in Cui et al. [1995] $-21.3^{\circ} \mathrm{N} 101^{\circ} \mathrm{E}$ are actually in Laos). Described from male holotype only.

MATERIAL. Thailand: Chantaburi prov.: Krating Resort env., $12.82^{\circ} \mathrm{N} 102.13^{\circ} \mathrm{E}, \mathrm{N}$. Vikhrev: 1-4.11.2009, $1 \mathrm{O}^{7}, 1$; $3-$ 6.12.2011, 2 O $^{7}, 3$ 90 ; Chiang Mae prov., $19.25^{\circ} \mathrm{N} 98.64^{\circ} \mathrm{E}$, $1130 \mathrm{~m}$ a.s.1., 15.11.2010, N. Vikhrev, 1 \%; Rayong prov., Khao Chamao NP, $13.0^{\circ} \mathrm{N} 101.7^{\circ} \mathrm{E}, 10.12 .2008$, N. Vikhrev, 1 o; Trat prov., Ko Chang Isl., $12.1^{\circ} \mathrm{N} 102.3^{\circ} \mathrm{E}, \mathrm{N}$. Vikhrev, 8-14.12.2011, $2 \overbrace{}^{\top} \overbrace{}^{\top}$.

SYNONYMY. The above listed males from Thailand fit Crosskey's description of $P$. longipila. They share the following set of diagnostic characters: frons unusually wide (at level of anterior pair of reclinate setae about $1 / 3$ of head width, instead of $1 / 4$ in most species of Pygophora); face white dusted; frons and antenna yellow; arista long plumose on almost whole length (Figs 6-7); abdominal pattern as described by Crosskey [1962: 491]; paralobes of hypopygium with a curious black process on the hind margin [Crosskey, 1962: 541, Fig. 78]; body size small (3.3-3.6 mm). The only discrepancy is that in Crosskey's redesription of $P$. longipila the minute hairs around the anterior inclinate seta were not mentioned. Dr. Joachim Ziegler (Berlin, Germany) kindly reexamined the lectotype of $P$. longipila in Museum für Naturkunde, HumboldtUniversität zu Berlin and confirmed that these hairs are indeed absent on the lectotype. I mentioned above the similar situation with $P$. enigma: in the type series $\left(2 \sigma^{7} \sigma^{T}\right)$ the supernumerary pair of inclinate setulae is absent according to Crosskey, whereas all my specimens have a supernumerary pair of inclinate setulae (though short and fine) and the anterior part of the fronto-orbital plates with 5-7 minute hairs. It seems that the presence of these hairs and setulae is a variable character. Crosskey [1962: 492-493] compared P. enig$m a$ with $P$. longipila and expressed some doubts in validity of $P$. enigma. I regard $P$. enigma as a good species which differs from $P$. longipila as recommended in the key fragment below, but in my opinion speci- 
mens from Thailand are conspecific with $P$. longipila. Females from Thailand are certainly conspecific to males and by Crosskey's key and redescription should be undoubtedly identified as $P$. nitidiventris.

Description of Pygophora orbiculata Cui et Zhang, 1995 [Cui et al., 1995] entirely fits $P$. longipila including the presence of hairs on the anterior $1 / 4$ of frontoorbital plates. The authors compared $P$. orbiculata with Pygophora flavida Crosskey, 1962, but did not compare it with either $P$. longipila or with $P$. nitidiventris.

Thus, Pygophora longipila Stein, $1910=$ Pygophora nitidiventris Malloch, 1929, syn.n. = Pygophora orbiculata Cui et Zhang, 1995, syn.n.

REMARKS. P. longipila is widely disrtributed in SE Asia: China, Yunnan prov.; Indonesia (Buru and Sumatra Isllands); Malaysia, Selangor prov.; Thailand: Chantaburi, Chiang Mae, Rayong and Trat provinces; Papua New Guinea. P. longipila seems to be related to $P$. enigma, known only from mountain areas of New Guinea. These species differ as follows $\left(O^{7}+\right)$ :

- Antenna (Fig. 4) and frons dirty blackish-brown, frontoorbital plates and pafacials brown-grey. Arista (Fig. 4) shorter haired, the longest hairs hardly longer than antenna width $\left(\bigcirc^{7}\right)$ or $1-1.5 \mathrm{x}$ as long as antenna width $\left(\bigcirc^{7}\right)$; upper hairs distinctly $\left(\sigma^{7}\right)$ or slightly $(+)$ longer that lower ones; arista plumose in basal $1 / 2\left(O^{7}\right)$ to $2 / 3(+)$. Fronto-orbital plates usually with 5-7 minute hairs in anterior $1 / 3$ and a pair of short and fine supernumerary inclinate setulae. Body length, $\mathrm{O}^{7}: 3.9-4.2 \mathrm{~mm}$; + : 4.6$4.8 \mathrm{~mm}$............................................. enigma Crosskey

- Antenna and frons yellow (Figs 6-7); fronto-orbital plates and pafacials yellowish-white. Arista (Fig. 6) long plumose on both sides, aristal hairs $2-2.5 \mathrm{x}$ as long as width of antenna; arista plumose almost all along its length. Fronto-orbital plates usually with 1-3 minute hairs in anterior 1/4 (Fig. 7). Body length, $\sigma^{7}: 3.3-3.6 \mathrm{~mm}$; $\circ$ : 3.6-4.0 mm. .......................................... longipila Stein

\section{Pygophora luteicornis Walker, 1858}

Figs 1-2.

Pygophora luteicornis Walker, 1858. Type locality: Indonesia, Aru Islands, the holotype collected by Alfred Russel Wallace himself. Paratype $10^{\top}$ : Dutch New Guinea, Sentani Lake $\left(2.6^{\circ} \mathrm{S} 140.6^{\circ} \mathrm{E}\right)$ Both localities are lowlands in contrast with Baliem Resort.

MATERIAL. Indonesia, W Papua prov., Wamena env., Baliem Resort, $2000 \mathrm{~m}$ a.s.1., $4.06^{\circ} \mathrm{S} 139.03^{\circ} \mathrm{E}, 16-25.12 .2014$, N. Vikhrev, $37 \sigma^{\top} \sigma^{\top}, 15$ 우.

NOTES ON MALE (Fig. 1). Setae on $p v$ surface of t2 may be better described as: dense row of 5-7 $p v$ near apex and 3-4 sparsely placed $p v$ in medium third. $f 3$ dark in basal 3/4 ([Crosskey, 1962: 452]: "legs entirely yellow").

DESCRIPTION OF FEMALE (Fig. 2). Body length: 6.3-6.8 mm. Head. Frons yellow-brown, face and gena yellowish-grey, occiput grey. Supernumerary inclinate setae absent. Antenna bright orange-yellow, postpedicel long, falling mouth margin by 0.2 of its length; postpedicel 6-7 times as long as wide. Thorax black. Scutum grey dusted with a pair of dark submedian vittae, median vitta hardly distinct, especially in presutural area. Presutural $a c$ in 2(3) rows. Legs. Coxae dark; trochanters dark or partly brown; femora black, tibiae yellow. $t 1$ with 1 long $p v$ and 2 short ad. Mid coxa without pair of long appressed setae. $f 2$ in basal half with 7-8 medium long $a v ; 3$ long $p v$ and 2 preapical $p d$. $t 2$ with $2 p d$. $f 3$ with irregular row of 5-6 av and 3 long $p v$ in basal part. $t 3$ with $1 a v, 2 a d, 2 p d$. Abdomen black with dense grey dusting except for yellowish lateral part of tergite $1+2$. Tergites 3 to 5 with large black median and lateral spots, which are almost fused.

Females $P$. absentiseta and $P$. luteicornis differ as follows:

- Antenna dark, only base of postpedicel yellow-brown; postpedicel rather short, falling mouth margin by 0.4 of its length. Scutum dark-grey dusted with median and a pair of submedian black vittae; scutal vittae are distinct either on post- and presutural areas. Trochanters yellow. $f 3$ dirty-yellow in basal 1/3-1/4. Body length: 5.5-5.7 mm..................................... o absentiseta Crosskey

- Antenna bright orange-yellow; postpedicel long, falling mouth margin by 0.25 of its length. Scutum with a pair of dark submedian vittae, median vitta hardly distinct especially in presutural area. Trochanters dark, at most partly brown. $f 3$ entirelly dark. Body length: 6.3-6.8 mm......................................... P luteicornis Walker

ECOLOGY. P. luteicornis was very common around Baliem Resort during my visit and I spent several hours observing the behavior of this species. Most Coenosiini genera may be found among grass vegetation or on stones or silt. Pygophora (also Cephalispa and some Coenosia like $C$. attenuata and C. agromyzina) prefers leaves of brushes and trees. Pygophora spend more time on the underside surface of leaves than on the upper one; they prefer brushes or trees growing near streams or ponds. Two times I was lucky to fix on camera females of $P$. luteicornis eating preys: Dicranomyia (Nealexandriaria) sp., Limoniidae (Fig. 2) and Cecidomyiidae sp.

\section{Pygophora papuana sp.n.}

Figs 8-9.

MATERIAL. Holotype $\sigma^{7}$ : Indonesia, W Papua prov., Lake Habbema (Fig. 8), $3350 \mathrm{~m}$ a.s.1., $4.14^{\circ} \mathrm{S} 138.71^{\circ} \mathrm{E}, 26.12 .2014$, N. Vikhrev.

DESCRIPTION. Male (Fig. 9). Body length: 6.7 $\mathrm{mm}$.

Head . Frons black; occiput and gena grey dusted; face and parafacials yellowish-grey dusted. Orbital setae remarkably long and strong; 2 reclinate setae; 2 strong inclinate and 3 supernumerary inclinate setae (2 pairs between inclinates, 1 pair between inclinates and reclinates). Gena apart from vibrissae with 5-6 remarkably strong setae. Antenna black, only base of postpedicel yellowish; postpedicel medium short, falling mouth margin by $0.30-0.35$ of its length; postpedicel 5 times as long as wide. Arista long, about $2 \mathrm{x}$ longer than length of postpedicel; long plumose in basal 1/3. Palpi dirty-yellow. Mentum black.

Thorax black. Scutum with a pair of thinly dusted submedian vittae on presutural area and grey dusted humeral calli. Pleura with grey dusting. Two pairs of strong presutural acrostichals instead of usual hairs; post ac also longer than in other Pygophora, in sparse 

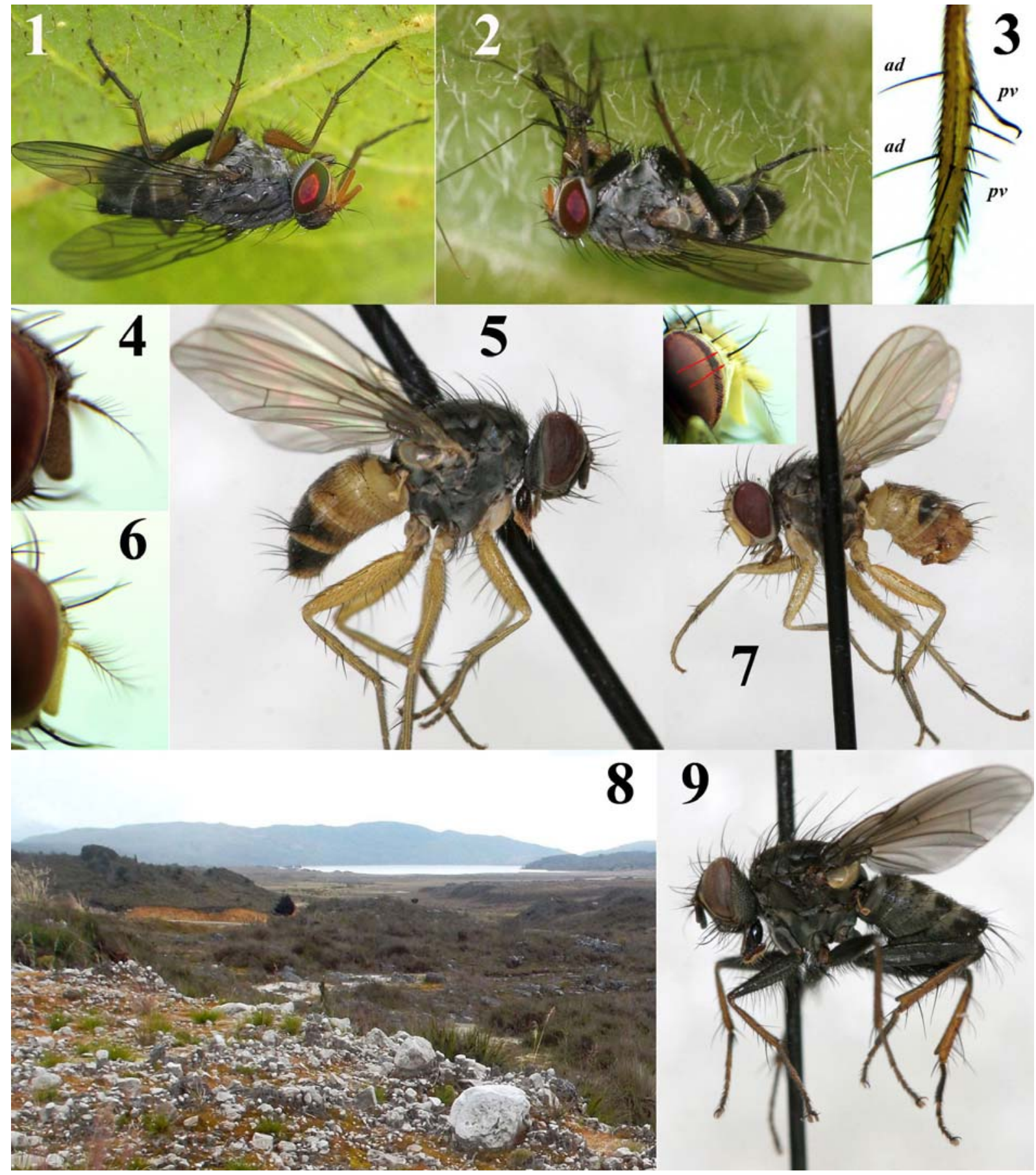

Figs 1-9. Pygophora. P. luteicornis: $1-O^{7}$ in the typical position underside a leaf; $2-9$ with a prey Dicranomyia (Nealexandriaria) sp.; $P$. absentiseta: $3-O^{7} t 3$, posterior view; $P$. enigma: $4-O^{7}$ antenna and arista; $5-O$, lateral view; $P$. longipila: $6-O^{7}$ antenna and arista; $7-\sigma^{7}$, lateral view and frontal view of head; $P$. papuana sp.n.: 8 - Lake Habbema, $3350 \mathrm{~m}$ a.s.l., type locality; $9-\sigma^{7}$ Holotype.

Рис 1-9. Pygophora. P. luteicornis: $1-\bigcirc^{7}$ в характерном положении на нижней стороне листа; 2 - самка с добычей Dicranomyia (Nealexandriaria) sp.; P. absentiseta: $3-\mathrm{O}^{\top}$ t3, вид сзади; $P$. enigma: $4-\sigma^{\top}$ антенна и ариста; $5-O$, вид сбоку; $P$. longipila: $6-\bigcirc^{7}$ антенна и ариста; $7-\bigcirc^{7}$, вид сбоку и голова спереди; P. papиапа sp.n.: 8 - озеро Хаббема, 3350 m н.у.м., типовое место; 9 - О' голотип.

2 rows; $d c 1+3$. Wings distinctly and evenly darkened. Calypters yellow.

Legs. Coxae, trochanters and femora black; tibiae and tarsi dark yellow. $t 1$ with long fine $p v$, long apical $a d$ and 2-3 shorter $a d$. Mid coxa with a pair of long appressed setae curved antero-laterally in apical part. $f 2$ in basal $2 / 3$ on ventral surface with straight setulae in arranged 3 rows; 1 strong and long (1.5-2x femur 
width) $a v$ beyond middle; $2-3 p p v$ in basal $1 / 3 ; 3$ strong and long $p v$ and 2 short spinulose $p v$ in median $1 / 3 ; 2 p d$ at apex. $t 2$ with 3 strong $p d . f 3$ with typical for Pygophora strong and long $p v$ in basal 1/3; 2 longer $a v$ in basal $1 / 3$ and 2 shorter $a v$ in apical $1 / 3$. $t 3$ with apical lobe; $1 a v, 4 a d, 3 p d, p v$ absent. Hind metatarsus dorso-ventrally curved.

Abdomen entirely dark. Tergites $1+2$ to 5 grey dusted, each with obtuse-triangle-shaped black posterodorsal mark (on tergite 5 it is noticeable that black obtuse triangle is formed as a result of fusion of medial and pair of lateral spots). Tergite 5 produced into a rounded dorsal keel with medium long marginal setae; ventrally tergite 5 with several long sinuous setae; tergite $7+8$ with long marginal setae.

Female unknown.

ETYMOLOGY. The name refers both to type locality and dark body colour.

DIAGNOSIS. P. papuana sp.n. is unmistakable: a very large species with entirely black body. Several other characters are unique for Pygophora: frons with 3 pairs of supernumerary inclinate setae; 2 pairs strong prst ac; $t 2$ with $3 \mathrm{pd}$; $t 3$ with $4 \mathrm{ad}$ and $3 \mathrm{pd}$.

ECOLOGY. P. papuana sp.n. was collected at 3350 $\mathrm{m}$ above sea level, such an elevation is a record for genus Pygophora. The male holotype was collected from rather short shrubs with small leaves, it is also atypical for Pygophora. Lake Habbema is a cold and rainy locality, during the wet season (from September to February), the day temperature is $10-20^{\circ} \mathrm{C}$, the night $-5-10^{\circ} \mathrm{C}$.

ACKNOWLEDGEMENTS. I thank Joachim Ziegler (Berlin) for examination of the lectotype of $P$. longipila. I want to express my thanks to Oleg Kosterin (Novosibirsk) for corrections of the text and Adrian Pont (Oxford) for his help and advices. I thank Oksana Eremenko (Kharkov) for various support during collecting trip in West Papua.

\section{References}

Crosskey R.W. 1962. A revision of the genus Pygophora Schiner (Diptera: Muscidae) // Transactions of the Zoological Society of London. Vol.29. P. 393-551.

Cui Y.-S., Xue W.-Q., Zhang C.-T. 1995. Five new species of the genus Pygophora from China (Diptera: Muscidae) // Entomologia Sinica. Vol.2. No.2. P.111-118.

Snyder F.M. 1965. Diptera: Muscidae // Insects of Micronesia. Vol.13. No.6. P.191-327.

Xue W., Zhang X. 2013. A key to the Pygophora Schiner (Diptera: Muscidae) from China with description of a new species // Oriental Insects. Vol.47. No.1. P.65-75. 